\title{
Analysis of the seismic process of the Bishkek geodynamic test site (Northern Tien Shan)
}

\author{
Vladimir Sychev ${ }^{*}$, Naylya Sycheva \\ Science Research Station of the RAS in Bishkek city, Kyrgyzstan
}

\begin{abstract}
Various characteristics of seismic process on the territory of Bishkek geodynamic proving ground are considered. Seismicity analysis is performed on the basis of earthquake catalogue, according to KNET network data. The catalog includes more than 10,000 seismic events that occurred from 1994 to 2019. To describe the energy distribution function of earthquakes, the Gutenberg - Richter law was used, as well as the position of nonequilibrium thermodynamics with the use of Tsallis statistics, which generalizes classical thermodynamics to the case of nonextensive systems. It is shown that the flow of earthquakes on the territory of the Bishkek geodynamic proving ground is a system with memory and long-range spatial correlations, and the study region itself is characterized as seismically active. The following seismic process characteristics are distributed in space and in time: $K_{\mathrm{SR}}$ seismogenic fracture parameter, seismotectonic deformation intensity, seismic activity, Tsallis parameter $q$ and constants $a$, as well as a parameter characterizing the slope of the repeatability graph (b-value).
\end{abstract}

\section{Introduction}

The Bishkek geodynamic proving ground (BGP, Northern Tien Shan), limited to $41.5^{\circ}$ $-43.5^{\circ} \mathrm{N}$ and $73^{\circ}-77^{\circ} \mathrm{E}$, lies within the central segment of the North Tien Shan seismogenerating zone and is the junction zone of the Tien Shan orogen and the Turan Plate. In fig. 1 the territory of BGP is conventionally indicated by a dotted line. The main tectonic structures of the study area at the neotectonic stage are the Kyrgyz meganticline (Kyrgyz ridge) and the Chuya depression located to the north. To the south of the Kyrgyz ridge are the Suusamyr, Kochkor and Jumgal depressions, separated by small ridges. To the west are the Talas, Bolshoi and Maly Karatau ridges, and to the east - the Kungei-Alatau and Terskey-Alatau ridges with the Issyk-Kul intermountain depression separating them.

The peculiarity of the seismic regime of the Northern Tien Shan is due to the geological structure, the intensity of the geodynamic processes occurring here and is associated with the ancient deep faults - the North Tien Shan, Kemin and Kungei. Such destructive earthquakes as Chilikskoe $M=8.3 \quad 1889$, Zhalanash-Tyupskoe $M=6.8 \quad 1978$, Sarykamyrskoe $M=6.8 \quad 1970$, Vernenskoe $M=7.3 \quad 1887$, Keminskoe $M=8.21911$ occurred on its territory. , Balasagunskoe $M=6.41475$, Belovodskoe $M=6.91885$,

* Corresponding author: koitash@mail.ru 
Suusamyrskoe $M=7.31992$ [1]. Seismic structures are, as a rule, edge faults or their segments. At the same time, the epicenters of most earthquakes in the Northern Tien Shan lie in a rather narrow strip that extends along the northern slope of the Kirghiz ridge, then extending eastward to the eastern plunge of the Kungei ridge and the Zailiyskiy ridge located to the north (Fig. 1). Earthquakes in the Northern Tien Shan are "crustal" earthquakes; their sources are located in the upper part of the earth's crust, or rather in the pre-Mesozoic basement. According to [2], earthquakes in the Tien Shan region occur at a depth of up to $30 \mathrm{~km}$.

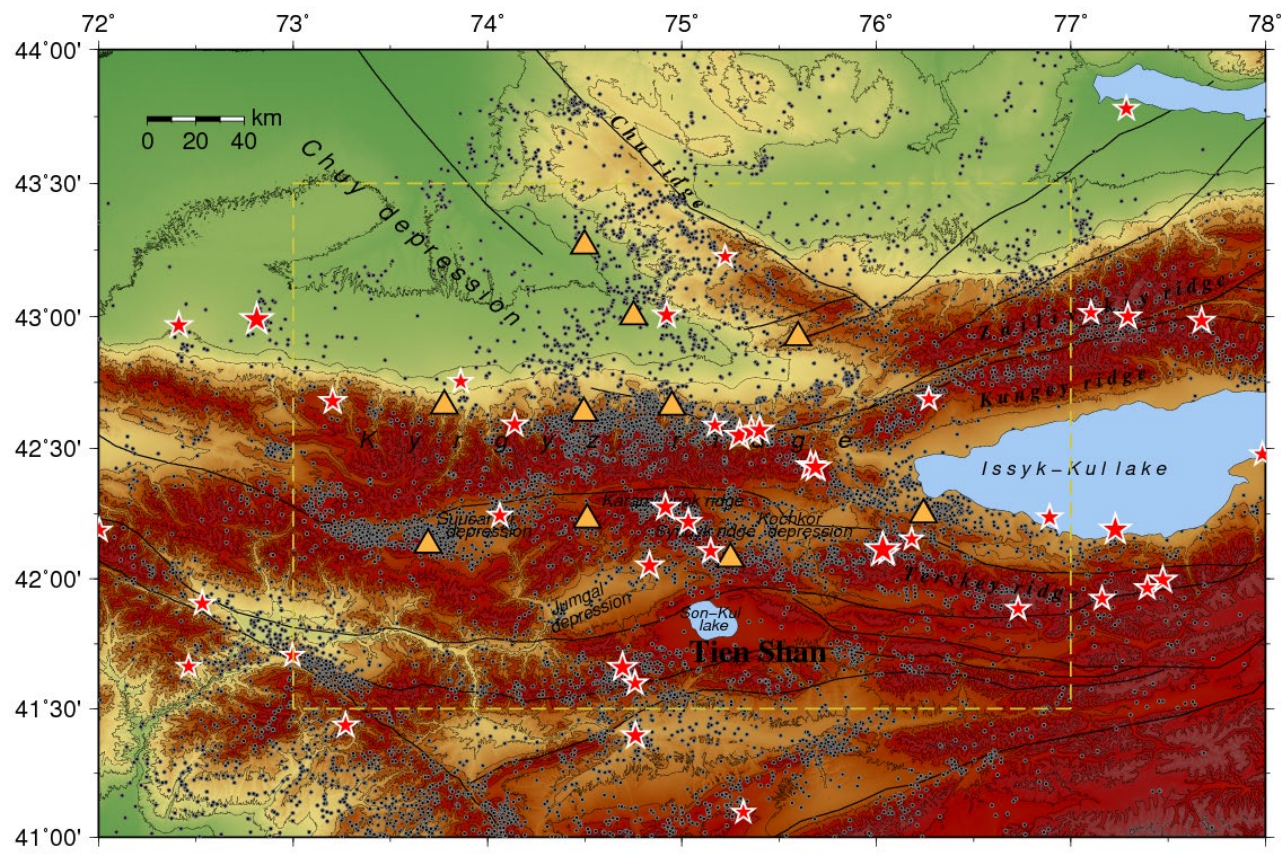

Fig. 1. Epicentral location of events (10 202 events, 1994-2019 y.). Triangles show position of KNET stations. Dotted line conventionally denotes BGP territory. The asterisks show the earthquakes position with $M \geq 4.4(K \geq 12)$.

To characterize the geodynamic process based on seismic data, various parameters are used, such as seismic activity, change in the angle of inclination of the recurrence graph, the parameter of the concentration of seismogenic ruptures, the intensity of seismotectonic deformations, etc. The Gutenberg-Richter law is traditionally used to construct the function of the distribution of earthquakes by energy. But along with the Gutenberg-Richter law, other models are sometimes used, in particular the exponential distribution [3] and the Tsallis distribution [4-6]. The use of non-intensive Tsallis entropy allows us to consider the seismological process from the standpoint of non-equilibrium thermodynamics, in which case the flow of earthquakes is presented in the form of an open system with memory and long-range spatial correlations both between individual events and between an individual event and the whole system.

The objective of this work is to analyze the seismic process of the territory of the Bishkek geodynamic test site based on the calculation of traditional parameters - seismic activity, STD intensity, seismogenic rupture parameter, b-value parameter of the Gutenberg - Richter distribution, as well as the application of the method of unconventional statistical analysis of the seismic process - non-extensive Tsallis statistics. 


\section{Methodology}

STD intensity. For a set of earthquakes that occurred in the volume of the medium $V$ over a period of time $T$, the averaged inelastic deformation caused by them is described by the tensor of the rate of rupture (seismotectonic) deformation, $\left\langle\varepsilon_{i j}>,[7]\right.$ :

$$
<\varepsilon_{i j}>=\frac{1}{G V T} \sum_{\alpha=1}^{N} M_{0}^{(\alpha)} m_{i j}^{(\alpha)}
$$

where the summation is carried out over seismic events, numbered using the index $\alpha, N$ is the number of events. In expression (1), $M_{0}{ }^{(\alpha)}$ is the seismic moment of the earthquake with number ${ }^{(\alpha)}, m_{\mathrm{ij}}{ }^{(\alpha)}$ is the directing tensor of the mechanism, $\mu$ is the shear modulus, $V$ is the volume under investigation, and $T$ is the study time.

In the case when the time period is expressed in years, the tensor $\left\langle\varepsilon_{i j}\right\rangle$ is also called the average annual increment of seismotectonic deformation (STD). In [7, 8], it was proposed to approximate (1) by the following expression

$$
<\varepsilon_{i j}>=\frac{1}{G V T} \sum M_{0}^{(\alpha)} \cdot \sum m_{i j}^{\alpha}=I_{\Sigma} \cdot \sum m_{i j}^{\alpha}
$$

where a scalar characteristic of the seismotectonic deformation increment, $I_{\Sigma}$, called the STD intensity is introduced.

b-value parameter. The most famous relation is the Gutenberg - Richter energy distribution law for earthquakes [9]:

$$
P(E) \sim E^{-\gamma},
$$

where $\gamma \approx 5 / 3, E$ is the earthquake energy [5]. In terms of the number of events with a magnitude $M$ exceeding $m$, the distribution law takes the form:

$$
N(M>m) \sim 10^{-\mathrm{bm}},
$$

where $N$ - denotes the number of events for a specified fixed period of time and in a given geographic region, $b$ - a constant ( $b$-value), in most cases takes a value of about 0.9 [10].

Crack concentration parameter $\boldsymbol{K}_{S R}$ has a clear physical meaning and is the ratio of the average distance between seismogenic ruptures that occurred in a certain seismically active volume $V_{0}$ during time $\Delta T$ to their average length [11]:

$$
K_{S R}=\eta^{-1 / 3} / l_{\text {cp }},
$$

where, $\eta=N / V_{0}$ - volumetric density (concentration) of ruptures, identified by the earthquakes that occurred; - $l_{\mathrm{cp}}=\sum_{j} l_{j} / N$ average rupture length by the ensemble of cracks;

$N$ is the total number of earthquakes in the range of energy classes $\left[K_{\min }, K_{\max }\right]$ that occurred in the elementary seismically active volume $V_{0}$ during the time $\Delta T ; l_{j}$ is the length of a single seismogenic rupture, which is estimated by the formula

$$
\lg l_{j}=a K_{j}+c
$$

where $K_{j}$ - is the energy class (or magnitude) of the earthquake. In different seismically active regions, the coefficients $a$ and $c$ may have different meanings. From the experience of using $K_{\mathrm{SR}}$ in a number of seismically active regions of the world, it follows that the most successful choice of coefficient values [12]: $a=0.244, c=-2.266$. In the case of using the 
magnitude instead of the energy class in expression (4), instead of $K_{j}$, you can substitute $M$, but the coefficients will change the values to the following: $a=0.440, c=-1.289$.

Nonextensive analysis. In 1988, Constantino Tsallis, to describe complex non-additive statistical systems, generalized the classical definition of the Boltzmann-Gibbs entropy by introducing into the expression the parameter $q$, which characterizes the degree of nonadditivity, and proposed the so-called nonextensive or non-additive entropy [4], which is determined on a discrete number of microstates $N$ by the following expression:

$$
S_{q}=k \frac{1}{q-1}\left(1-\sum_{i=1}^{N} p_{i}^{q}\right) ; \quad \sum_{i=1}^{N} p_{i}=1
$$

where $p_{i}$ is the probability that the system is in the $i$ - state, $N$ is the number of states of the system, $k$ is some positive constant that determines the unit of measurement of entropy and in physical formulas serves for a bundle of dimensions, such as the Boltzmann constant. The Boltzmann statistics, corresponding to the limit $q \rightarrow 1, q>1$, indicates the presence of long-range correlations and memory in a nonequilibrium system when additivity is violated. Thus, the Tsallis entropy is no longer an extensive function.

The analysis of the flow of earthquakes, as an open nonequilibrium system, is based on the energy distribution function of earthquakes proposed in [13] based on the well-known model of stick-slip earthquakes - "discontinuous sliding" of two plates over each other along a fault in the presence of friction [14] and the principles non-extensive statistical physics.

Using this model and the principle of maximum entropy in [13], an analytical expression was obtained for the energy distribution function of earthquakes, which generalizes the empirical Gutenberg - Richter function. In turn, [15] clarified this model using a more realistic relationship between the energy of the earthquake and the size of the fragments between the sliding planes. An analytical expression is obtained that describes the generalized Gutenberg - Richter law, which relates the cumulative number of earthquakes with a magnitude exceeding the threshold value with the Tsallis parameter $q$ :

$$
\log \left(\frac{N\left(M>M_{t h}\right)}{N}\right)=\left(\frac{2-q}{1-q}\right) \log \left[1-\left(\frac{1-q}{2-q}\right)\left(\frac{10^{M_{t h}}}{a^{2 / 3}}\right)\right]
$$

where $N\left(M>M_{t h}\right)$ is the number of earthquakes with energies greater than the threshold value $M_{t h}$, and $M \sim \log (E), E$ is the earthquake energy, $N$ is the total number of earthquakes, a is the proportionality constant between the earthquake energy $E$ and the size of the fragment of blocks between faults and has the dimension of the bulk energy density $[6,15-17]$.

The above expression describes well the energy distribution of earthquakes in the entire range of magnitudes, in contrast to the empirical Gutenberg - Richter formula [15]. Moreover, the evaluation of the Tsallis parameter $q$ is stable with respect to the selection of the threshold value of magnitude $M_{t h}$, than the evaluation of the parameter $b$-value, which is more demanding to select a linear section of the repeatability graph [17].

Equation (8) makes it possible to estimate the degree of nonextensiveness in the region under consideration. In addition, as noted in $[5,6]$, this equation can be considered a generalized equation for the distribution of earthquakes by energy, since at magnitudes above a certain threshold value, this distribution reduces to a Gutenberg - Richter expression of the form with the $b$-value [6]:

$$
b=\frac{2-q}{q-1}
$$


Many publications indicate that the value of the parameter $q$ can be used as a measure of the stability of the active tectonic zone [6,17-27]. A sharp increase in the parameter $q$ indicates an increase in the interaction between fault blocks and their fragments and implies a deviation from the equilibrium state [17].

The study of seismotectonic deformations and STD intensity of the territory of the Bishkek geodynamic polygon was carried out in the works [28, 29]. The use of Tsallis statistics was used to study the aftershock sequence of the Suusamyr earthquake and the earthquake catalog as a whole. [30].

The objective of this work is to analyze the seismic process of the Bishkek geodynamic proving ground based on the calculation of traditional parameters - seismic activity, STD intensity, seismogenic rupture parameter, b-value parameter of the Gutenberg - Richter distribution, as well as nonextensive analysis using Tsallis statistics.

\section{Catalog and Region}

The seismological network KNET is located on the territory of BGP (see Fig. 1), consisting of ten digital broadband stations, which allows registering local and regional seismicity. To date, the catalog of earthquakes obtained from the data of the KNET network includes more than 10,000 thousand seismic events that occurred in 1994-2019 (Fig. 1). Over the years of operation, the seismological network registered 46 moderate earthquakes with $M \geq 4.4(K \geq 12)$, of which 24 occurred on the territory of BGP. For the period under consideration, the maximum magnitude $(M=6)$ is characterized by the Kochkor earthquake, which occurred 25.12.2006.

For the research, a catalog of seismic events was used according to the KNET network data for 1994-2019. During this time, 10202 events took place in the study area (see Fig. 1). In fig. 2 shows the distribution of events by class, depth and time. The main part of the catalog consists of weak events with $M=1.1-2.2(K=6-8$, Fig. 2a), a representative sample of the catalog includes events with $1.6 \leq M \leq 5(7 \leq K \leq 13$, Fig. 2b), events in time are unevenly distributed (Fig. 2c); the hypocenters of most of the events are located at a depth of $0-15 \mathrm{~km}$ (Fig. 2d). 

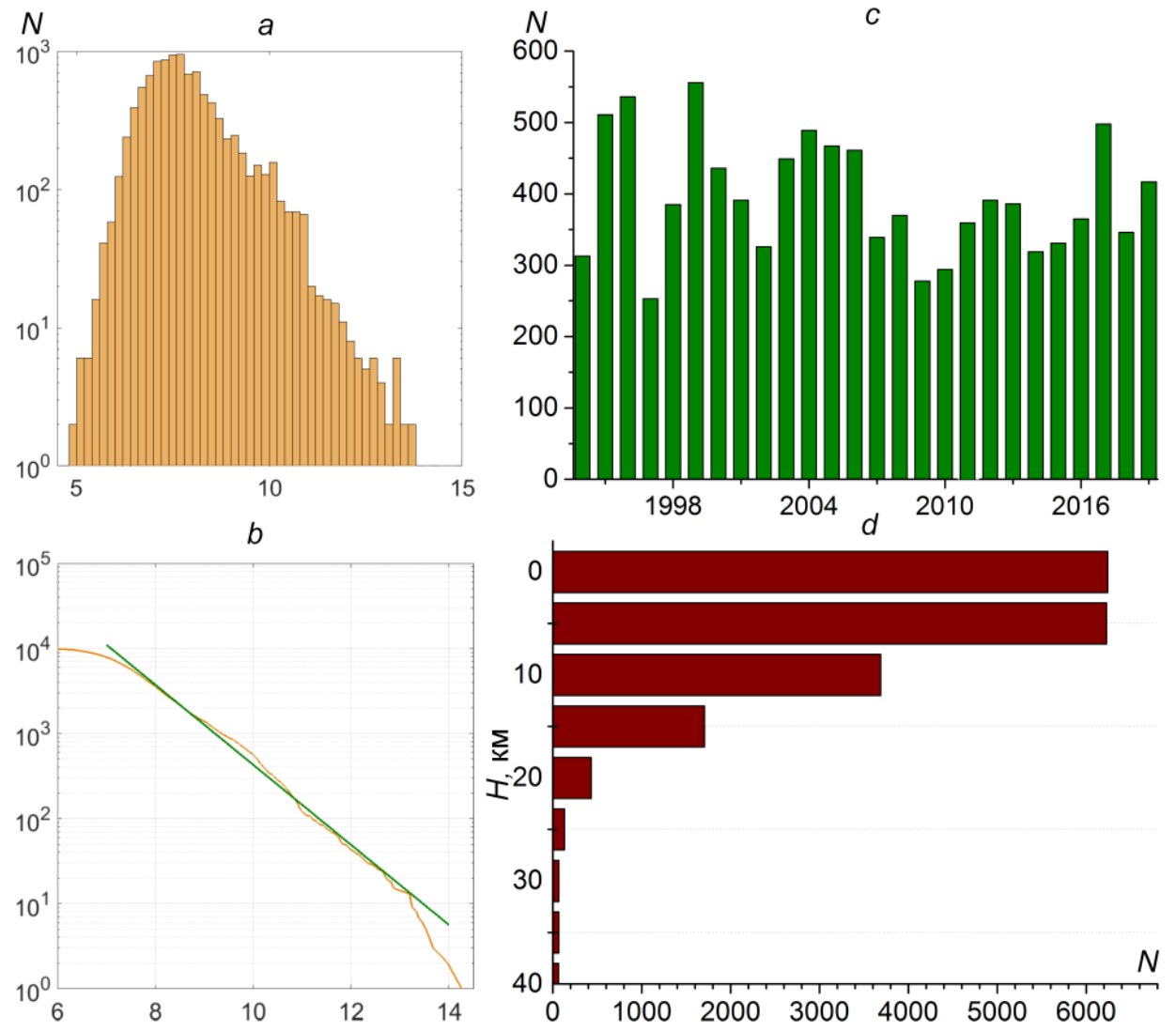

Fig. 2. Statistical characteristics of the catalog according to the KNET network (more than 10,000 events): $a$ - repeatability graph; $b$-Gutenberg - Richter distribution; $c$ - time distribution of events; $d$ - depth distribution of events

\section{Results}

The calculation of various parameters characterizing the seismic process in the study area is carried out in time and space.

To calculate the distribution of the studied parameters (seismic activity, STD intensity, seismogenic rupture parameter, Tsallis parameter $q$ and $b$ - value) over the territory of the BGP, the geostructural region was subdivided into unit cells with a size of $0.5^{\circ}$ and the shift was $0.25^{\circ}$. The lower limit of the depth of the investigated layer is $30 \mathrm{~km}$.

Spatial distribution of the investigated characteristics. The distribution of seismic activity (the number of earthquakes in the studied cell) is shown in Fig. 3. The position of earthquakes with $M \geq 4.4$ that occurred on the territory of the BGP during the study. The maximum seismic activity $(\mathrm{N}>900)$ falls on the central part of the Kyrgyz Ridge $\left(74.25^{\circ}-\right.$ $\left.75.25^{\circ} \mathrm{E}\right)$. However, in this area during the study, one event occurred with $M \geq 4.4$. The main part of earthquakes with $M \geq 4.4$ (20 events) is located in areas where the number of earthquakes $N>300$. The distribution of the logarithm of the STD intensity in the territory of the BGP is shown in Fig. 4. The maximum value of the logarithm of the STD intensity $I_{\Sigma}$ is $10^{-8}$ per year ${ }^{-1}$ and is typical for the zone of the Kochkor earthquake of December 25, 2006, $M=6$. The value of the STD intensity in the eastern part of the Kyrgyz ridge is 
slightly lower. The main part of events with $M \geq 4.4$ in areas where $\lg I_{\Sigma}$ is more than $10^{-9}$ per year ${ }^{-1}$.

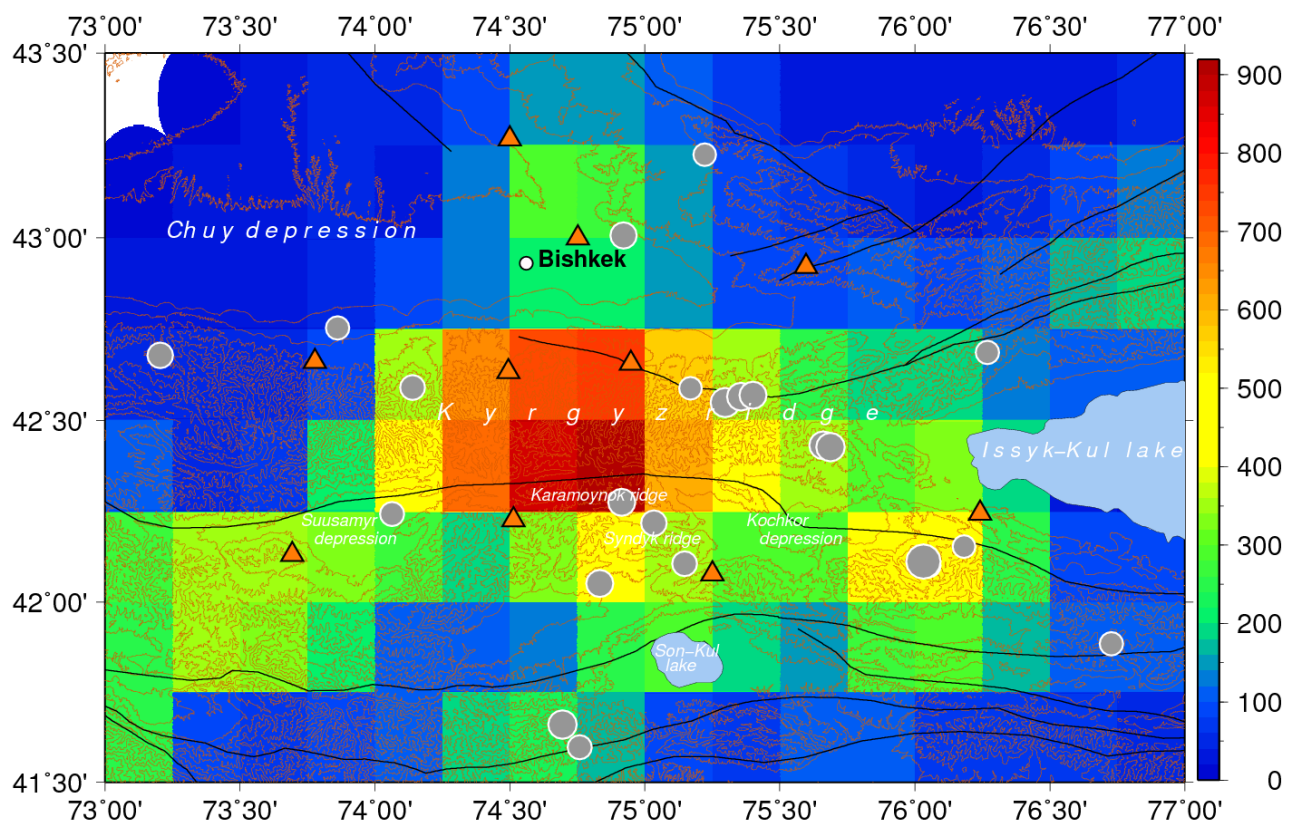

Fig. 3. Number distribution of earthquakes on BGP territory according to KNET network data (19942019).

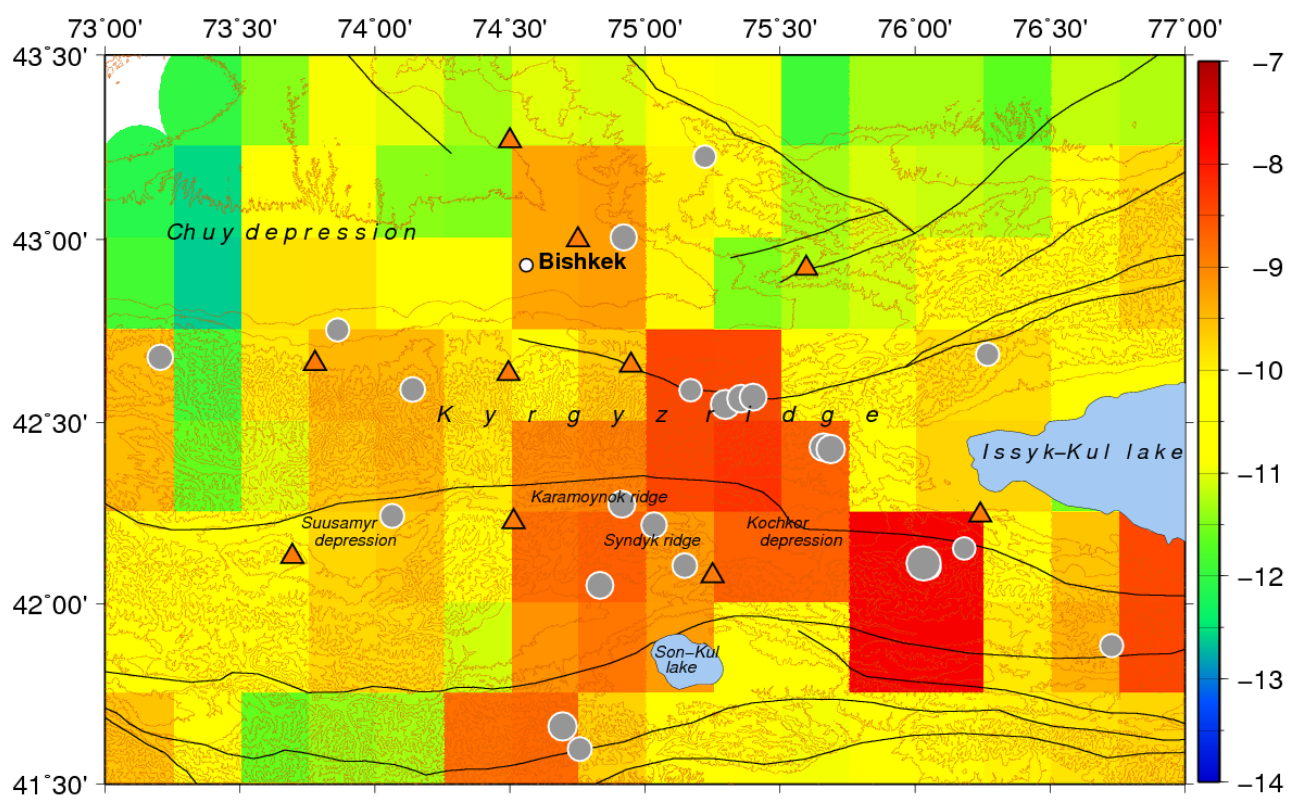

Fig. 4. Distribution of the logarithm of the STD intensity on BGP territory according to KNET network data (1994-2019).

Parameter of seismogenic fractures $K_{\mathrm{SR}}$. Each earthquake represents a displacement along a break in the earth's crust. The accumulation of seimogenic ruptures leads to an unstable state of the geodynamic system, in which a general rupture can occur (a large 
seismic event). According to expression (5), an increase in the number of cracks in the medium leads to a decrease in the seismogenic fracture parameter - the more cracks, the lower the value of this parameter. The distribution of the $K_{\mathrm{SR}}$ parameter on the territory of the BGP is shown in Fig. 5. Active accumulation of cracks (seimogenic fractures, $K_{\mathrm{SR}}<15$ ) is typical for the central and eastern parts of the Kyrgyz ridge, for the Kungei and Terskey ridges, the Kochkor depression and the central part of the Talas-Fergana fault. The positions of earthquakes with $M \geq 4.4$ are shown on the same map; $83 \%$ of these events occurred in the territory characterized by $K_{\mathrm{SR}}<10$. In [31], $K_{\mathrm{SR}}<8$ is indicated as a critical value when a large seismic event can occur. The highlighted areas are potentially dangerous, where further fracture accumulation can lead to a large earthquake.

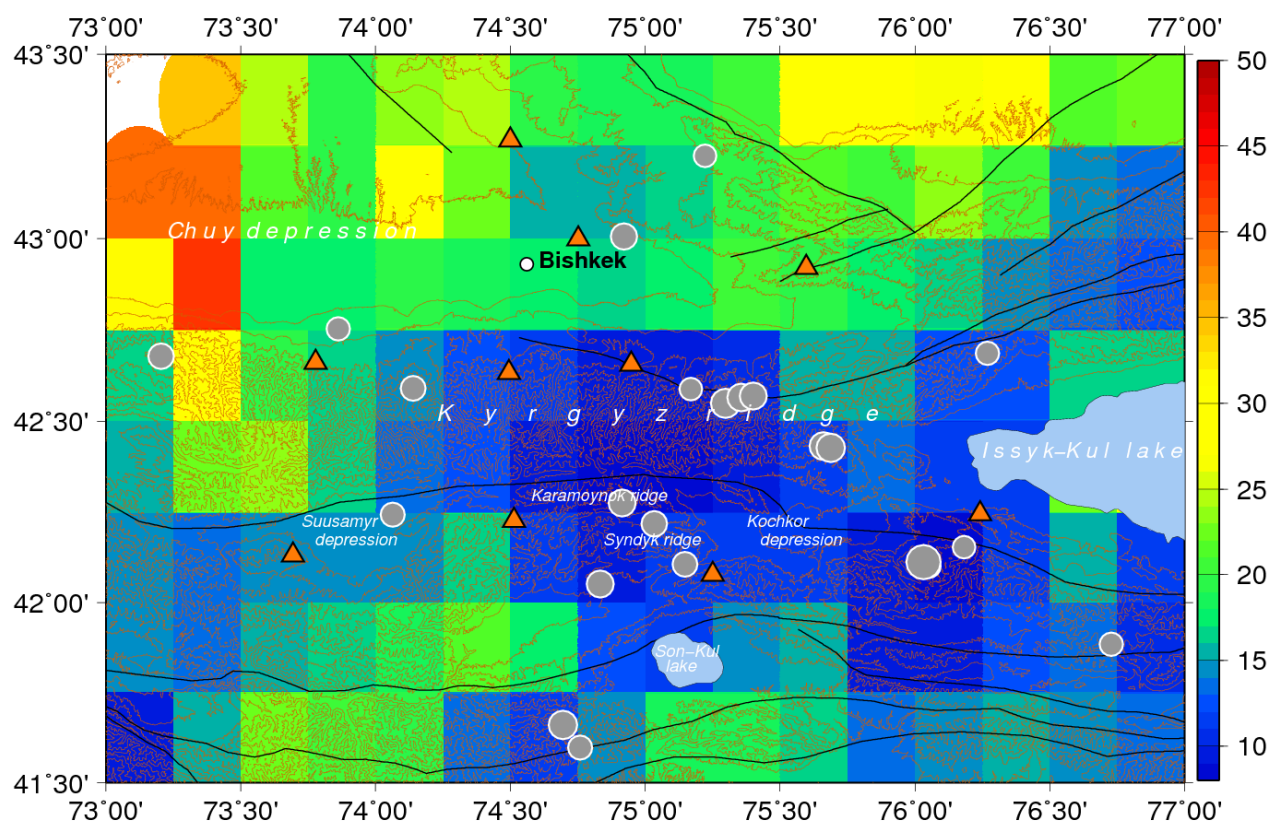

Fig. 5. Distribution of the coefficient of seismogenic ruptures on BGP territory according to KNET network data (1994-2019).

$b$-value. In fig. 6 shows the distribution of the $b$-value parameter calculated according to the Gutenberg - Richter law, expression (4), for each considered cell of space. The maximum value of this parameter is observed in the eastern part of the Kyrgyz ridge and along the southern flank of the Suusamyr depression. In the eastern part of the Kyrgyz Ridge, several earthquakes with $M \geq 4.4$ occurred with subsequent aftershock events, which affected the number of weak earthquakes. In the area of the Suusamyr depression, the aftershock process of the Suusamyr earthquake on August 19, $1992 M=7.3$, which lasted for a long time, led to an increase in weak events. 


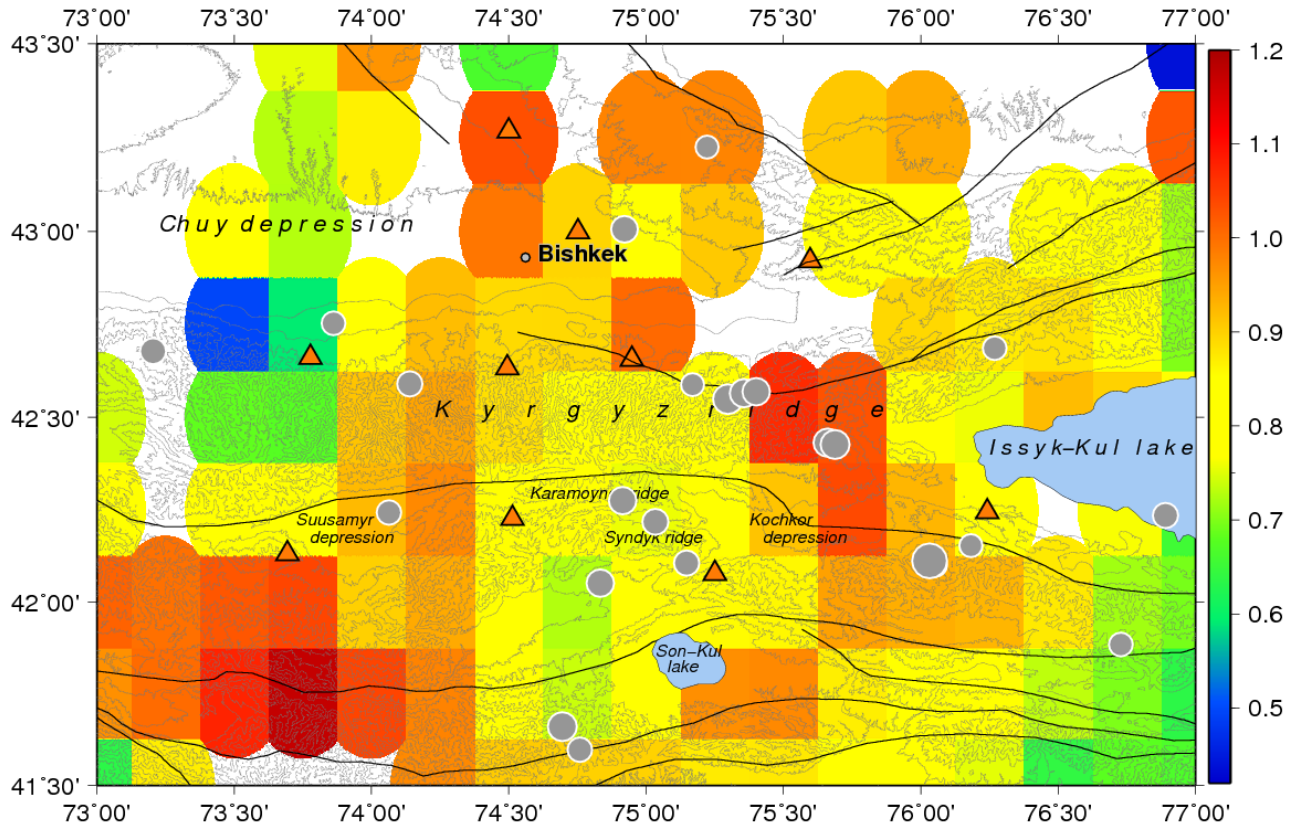

Fig. 6. b-value distribution of on BGP territory according to the data of the KNET network (19942019).

Tsallis parameter $q$. To determine the Tsallis parameter $q$ and the constant $a$, characterizing the seismic process of the BGP territory as a whole, we analyzed the earthquake catalog based on the KNET network data for 1994 - 2019. The calculation of these parameters is based on expression (8). The constructions necessary for calculating these parameters and the obtained values are shown in Fig. 7. The graph shows the energy distribution function of earthquakes in blue, and the approximation in red using the calculated values $a=529.34$ and $q=1.509$. The figure also shows the traditional approximation by the Gutenberg - Richter law (black line) and the parameter $b$-value $=0.85$ calculated from the linear section of the graph. The obtained value of the Tsallis parameter characterizes the studied region as seismically active and is in good agreement with the $q$ values for other seismically active regions. [6, 15-17, 19-22; and etc.].

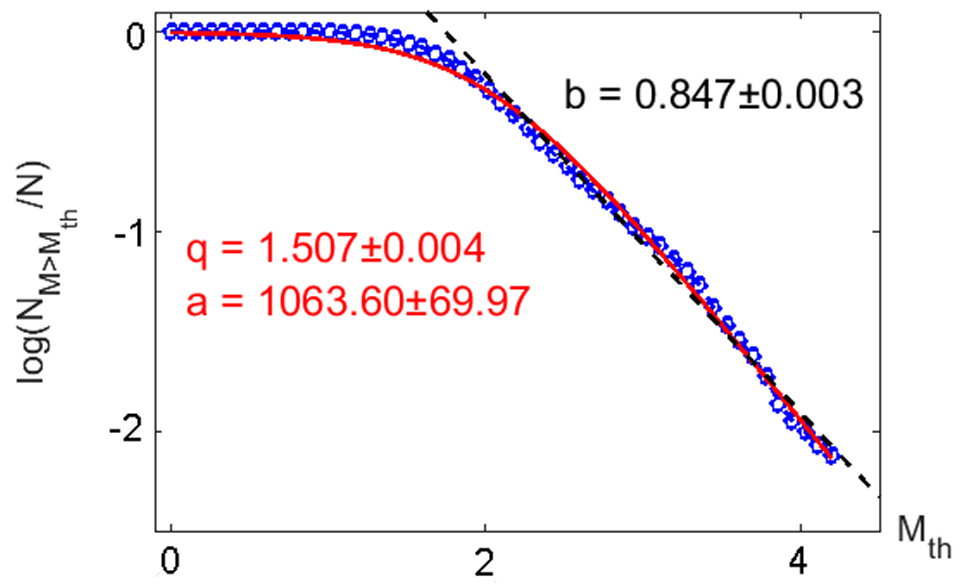


Fig. 7. The repeatability graph for earthquakes on the territory of BGP (blue color) and its approximation: red color - calculation based on expression (8), black color - Gutenberg - Richter law (expression (2)).

In fig. 8 shows the areal distribution of the Tsallis parameter q for the BGP territory for each considered space cell. The minimum value of this parameter in the study area is $q=$ 1.25 , the maximum $q=1.75$. The epicentral position of the earthquake with $M \geq 4.4$, which occurred on the territory of the BGP, is shown on the same map. Half of these events occurred in areas where $q \geq 1.6$. It is quite possible that some of these events were accompanied by aftershock processes leading to an increase in the Tsallis parameter $q$. During the aftershock process, the unstable state of this area remains, the active seismic process continues, and the seismogenic zones have not yet returned to a state of relative equilibrium.

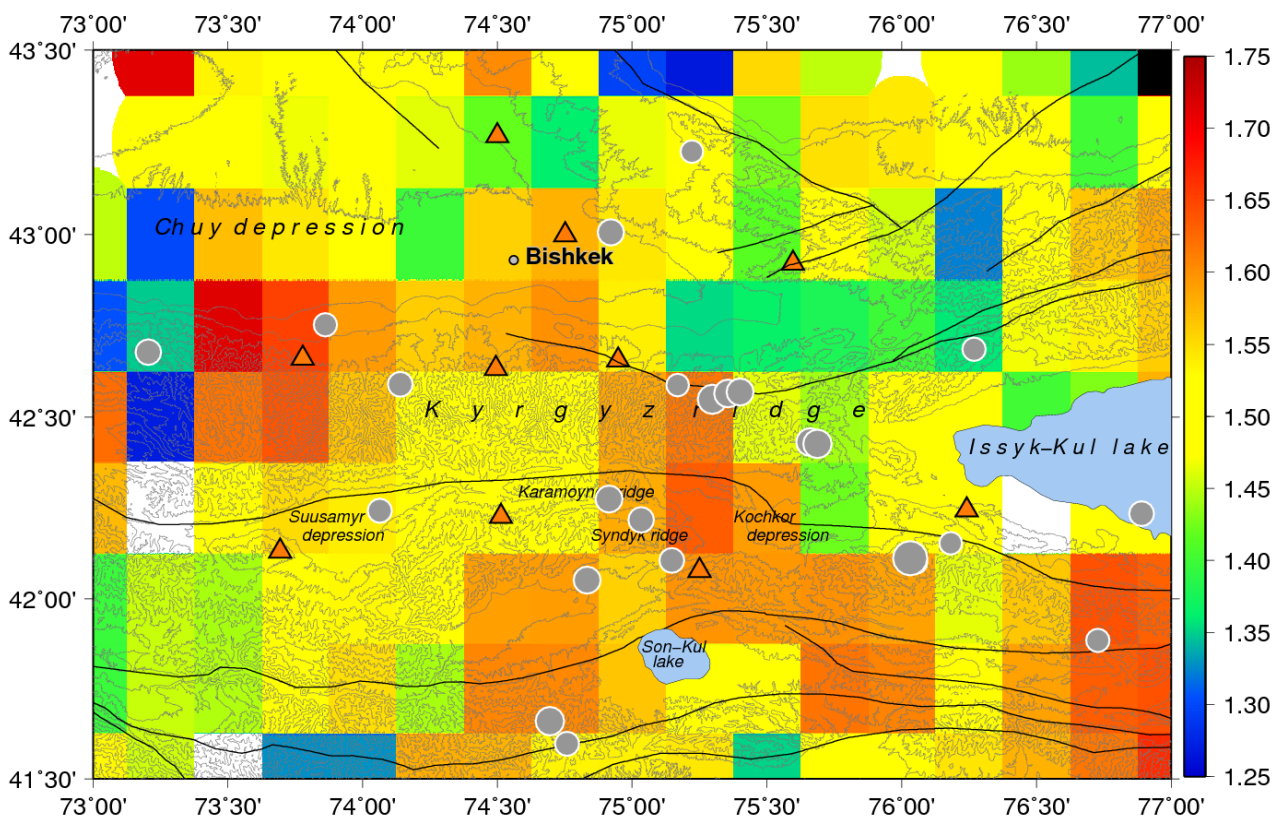

Fig. 8. Distribution of the Tsallis parameter $q$ on the territory of BGP according to the data of the KNET network (1994-2019).

Time distribution of the investigated characteristics. To calculate the characteristics under consideration in time on the territory of the Bishkek geodynamic test site, data from 1999 to 2019 were used, which is due to the fact that the seismological network began to work in real time from mid-1998, which increased the quality of the network to $98 \%$.

The distribution of STD intensity in time was calculated based on expression (2). The summation of seismic moments $M_{0}$, normalized to the product of time $T$, volume $V$ and shear modulus was carried out for every 60 days from 1999 to 2019. To determine the scalar seismic moment (M0) from the magnitude $(M)$, the following expression is used: $\log$ $\left(M_{0}[\mathrm{dyn} \cdot \mathrm{cm}]\right)=15.4+1.6 M[32]$, and the shear modulus is taken to be $3.0 \times 10^{11} \mathrm{dyn} / \mathrm{cm}^{2}$ [33]. Simultaneously with the STD intensity, the number of earthquakes was calculated for the considered time interval.

The distribution of the number of earthquakes and the logarithm of the STD intensity for the BGP territory is shown in Fig. 9. On the same graphs, vertical lines show the dates of earthquakes with $M \geq 4$.4. Some dates of these earthquakes coincide with the peak seismic activity, which may indicate aftershock activity after these seismic events. The maximum number of earthquakes coincides with the time of the earthquake (April 21, 
2017, $M=4.4$ ), which was accompanied by aftershocks (72 events). It can also be noted that not all earthquakes with $M \geq 4.4$ are accompanied by an aftershock process (Fig. 9a). The peak values of the STD intensity coincide with the dates of earthquakes with $M \geq 4.4$ (Fig. 9b). The maximum peak value of the STD intensity $I_{\Sigma}=10^{-9}$ year $^{-1}$ coincides with the time of the Kochkor earthquake (25.12.2006, $M=6$ ). The background level of STD intensity corresponds to $I_{\Sigma}=10^{-11}$ year $^{-1}$.
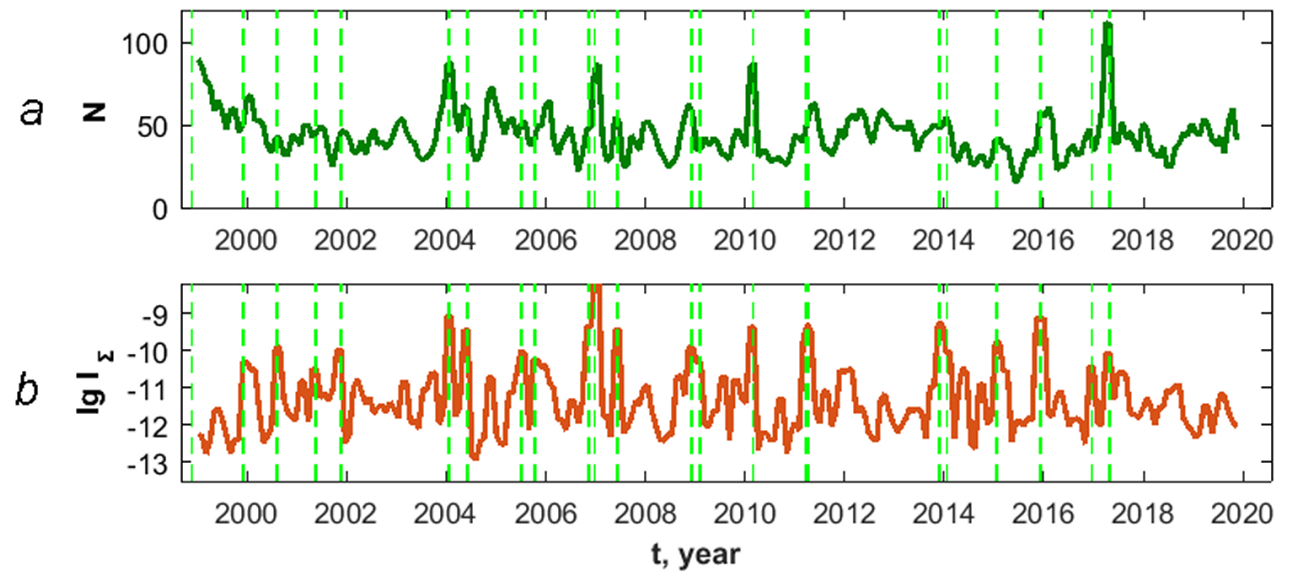

Fig. 9. Time distribution of the number of earthquakes (a), the decimal logarithm of the STD intensity (b) for BGP territory according to KNET network data (1994-2019).

In fig. 10 shows the distribution of the Tsallis $q$ parameters, the $a$ constant and the $b$ value calculated in two ways. In the first case, the $b$-value is calculated based on expression (9). In the second case, the Gutenberg - Richter distribution is calculated for a specified number of events and the slope of the repeatability graph is determined, expression (2). The distributions of these parameters are marked with vertical dashed lines with the dates of earthquakes with $M \geq 4.4$.

The change in the Tsallis parameter $q$ for the period under consideration is shown in Fig. 10a. The value of this parameter ranges from 1.3 to 1.6. For the entire catalog, the value of the Tsallis parameter $q=1.509$ was obtained; on the graph this level is marked with a red horizontal line. For the period under study, the value of this parameter exceeds the value obtained for the entire catalog, with the exception of the time interval at the 20132014 level, when there is a significant decrease relative to the average level. According to the distribution of the number of earthquakes (see Fig. 10a), this period is characterized by the lowest seismic activity for the period under study. A decrease in the value of the $q$ parameter indicates a weakening of spatial correlations. As already noted, the Tsallis parameter can serve as a measure of the instability of a seismically active area. An increase in this parameter characterizes the beginning of an active seismic process. In full accordance with these provisions, most of the events noted in the figure are accompanied by an increase in the Tsallis parameter $q$. Then, almost immediately after the earthquake, together with the release of accumulated stresses, this parameter decreases, which means that the system returns to its previous metastable state. On the contrary, the constant $a$ (Fig. $10 \mathrm{~b}$ ), which has the dimension of the volumetric energy density, increases during this period. This may mean the involvement of a larger area in an active seismic process due to less energetic aftershocks if the main event is accompanied by a series of aftershocks. 
a
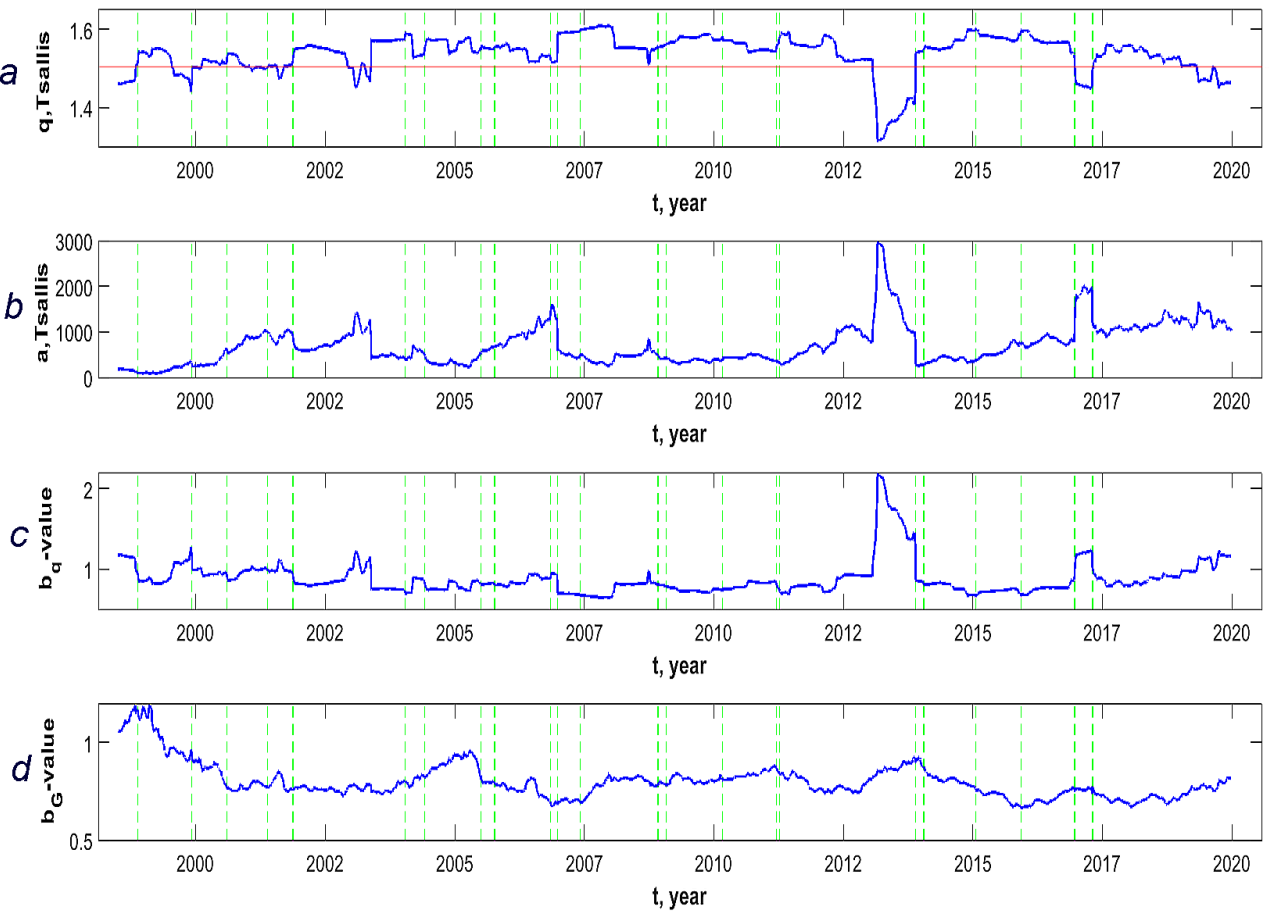

Fig. 10. Change in the Tsallis parameters $q$ (a) and $a(\mathrm{~b}), b$-value calculated from the value of $q$ (c) and from the Gutenberg - Richter distribution (d) for BGP territory according to KNET network data (1999-2019).

The time distribution of the $b$-value parameter obtained by the two methods generally coincides with the exception of the period 2013-2014, when the $b$-value calculated from $q$ (Figure 10c) increases significantly with respect to the $b$-value calculated from the Gutenberg-Richter graph (Figure 10d). The b-value changes over time in a significant range of $0.8-1.2$. The b-value determined from the seismicity of the BGP is 0.85 (Fig. 7). An increase in this parameter indicates an increase in weak events. As a rule, the location of events with $M \geq 4.4$ falls on periods of decreasing $b$-value.

\section{Conclusion}

Various parameters characterizing the seismic process of the Bishkek geodynamic test site are considered - seismic activity, STD intensity, seismogenic fracture parameter, Tsallis parameters $q$ and $a$, as well as the inclination angle (b-value) of the Gutenberg - Richter distribution. The combination of these parameters makes it possible to assess the geodynamic process occurring in the area of the junction of the Tien Shan orogen and the Kazakh platform (BGP). For the analysis, we used the catalog of earthquakes according to the KNET network data (more than 10,000 events) that occurred in the Northern Tien Shan from 1994 to 2019. Changes in the studied parameters are considered both in space and in time. During the period under consideration, 24 earthquakes with $M \geq 4.4$ occurred on the territory of BGP. The maximum seismic activity is characteristic of the central part of the Kyrgyz ridge $\left(74.25^{\circ}-75.25^{\circ} \mathrm{E}\right)$. The maximum value of the logarithm of the STD intensity $I_{\Sigma}$ is $10^{-9}$ per year $^{-1}$ and is typical for the zone of the Kochkor earthquake of December 25, $2006, M=6$. Active accumulation of seismogenic ruptures occurs in the eastern part of the Kyrgyz Ridge, in the area of the Kochkor depression and along the southern flank of the 
Suusamyr depression. The highest level of long-range spatial correlations is observed in the eastern part of the Kyrgyz ridge and in the area of the Suusamyr depression. It is shown that the flow of earthquakes on the territory of the BGP is a system with memory and longrange spatial correlations, and the study region itself is characterized as seismically active. The value of the Tsallis parameter $q$ in time exceeds the value of $q$ for the entire catalog, except for the period 2013-2014. The $b$-value also changes over time; a low value of this parameter corresponds to the period of absence of earthquakes with $M \geq 4.4$.

\section{Financing sources}

The research was partially carried out within the framework of the state assignment of Research Station of the Russian Academy of Sciences in Bishkek sity (thems № AAAA-A19-119020190064-9 and № AAAA-A19-119020190066-3).

\section{References}

1. Geodynamics of the Talaso-Ferghana Tian Shan Fault and natural disasters in Central Asia G ed. K.E. Abdrakhmatov (Bishkek: Arashan-Press House) p 229 (2009)

2. F.N. Yudakhin Geophysical fields, depth structure and seismicity of Tian Shan(Frunze: Ilim) 246 p (1983)

3. E.E. Damaskinskaya, I.A. Panteleev, D.I. Frolov, N.F. Vasilenko Geosystems of Transition Zones vol 23 pp 245-251 (2018)

4. C. Tsallis J. of Statistical Physics. vol 52 (1-2) pp 479-487 (1988)

5. N.V. Sarlis, E.S. Skordas, P.A. Varotsos Physical Review E August American Physical Society (APS) (2010)

6. F. Vallianatos, G. Michas, G. Papadakis Physica A: Statistical Mechanics and its Applications vol 41415 November pp 163-173 (2014)

7. S.L. Yunga Methods and results of studying seismotectonic deformations (Moscow: Science) p 191 (1990)

8. A.A. Lukk, S.L. Yunga Izvestiya of the Academy of Sciences of the USSR. Physics of the Solid Earth 10 pp 24-43 (1979)

9. B. Gutenberg, C.F. Richter Bull. of the Seismological Society of America vol $34 \mathrm{pp}$ 185-188 (1944)

10. K. Kasahara Mechanics of earthquakes (Moscow: World) p 264 (1985)

11. G.A. Sobolev, A.D. Zavyalov Soviet Physics. Doklady 2521 pp 69-71 (1980)

12. Yu.V. Riznichenko Earthquake Physics Study (Moscow: Science) pp 9-27 (1976)

13. O. Sotolongo-Costa, A. Posadas Physical Review Letters February vol 924 (2004)

14. S.R. Brown, C.H. Scholz, J.B. Rundle Geophys. Res. Lett. vol 182 pp 215-218 (1991)

15. R. Silva, G.S. Franca, C.S. Vilar, J.S. Alcanis Phys. Rev. E. vol 73026102 (2006)

16. L. Telesca Entropy vol 13(7) pp 127-1280 (2011)

17. Complexity of Seismic Time Series: Measurement and Application Edited by Tamaz Chelidze Filippos Vallianatos Luciano Telesca 2016 Amsterdam Netherlands: Elsevier p 548 (2018)

18. T. Matcharashvili, T. Chelidze, Z. Javakhishvili, N. Jorjiashvil, U. Fra Paleo Comput. Geosci vol 37 pp 1627-163 (2011)

19. G. Papadakis, F. Vallianatos, P. Sammonds Tectonophysics vol 608 pp 1037-1048 (2013)

20. G. Papadakis, F. Vallianatos, P. Sammonds Pure Appl. Geophys. vol 172 p $1923-$ 1931 (2015)

21. G. Papadakis, F. Vallianatos, P. Sammonds. Phys. A 456 pp 135-144 (2016) 
22. G. Papadakis A PhD Thesis University College London (2016)

23. L. Telesca, C.C. Chen Nat. Hazards Earth Syst. Sci. vol 10 pp 1293-1297 (2010)

24. L. Telesca Tectonophysics vol 494 pp 155-162 (2010)

25. L. Telesca Phys. A 389 pp 1911-1914 (2010)

26. L. Telesca Terra Nova 22 (2) pp 87-93 (2010)

27. S.M. Valverde-Esparza, A. Ramirez-Rojas, E.L. Flores-Marquez, L. Telesca. Acta Geophys 60 pp 833-845 (2012)

28. N.A. Sycheva, L.M. Bogomolov, V.N. Sychev, A.D. Kostuk Geophysical research vol 102 pp 37-46 (2009)

29. N.A. Sycheva, A.N. Mansurov Geodynamics and Tectonophysics vol 84 pp 809-825 (2017)

30. V.N. Sychev, N.A. Sycheva, S.A. Imashev Geosystems of Transition Zones vol 31 pp 35-43 (2019)

31. A.D. Zavyalov Medium-term earthquake forecast: fundamentals, methodology, implementation (Moscow: Science) p 254 (2006)

32. Yu.V. Riznichenko Seismology problems. Selected works (Moscow: Science) p 408 (1985)

33. Yu.V. Riznichenko, O.V. Soboleva, O.A. Kuchay, R.S. Mikhaylova, O.N. Vasilieva Izvestiya of the Academy of Sciences of the USSR 10 pp 90-104 (1982) 